\title{
A Consideration of Power Structures (and the Tensions They Create) in Library Assessment Activities
}

\author{
Ebony Magnus \\ Southern Alberta Institute of Technology, Canada \\ Maggie Faber and Jackie Belanger \\ University of Washington, USA
}

\section{Introduction}

The aim of this paper is to explore some of the sites of tension in our assessment work, in particular what it means to engage in "practical" assessment and the potential challenges of an (over)emphasis on this way of approaching assessment. Our goal is not to argue for a singular view of how we should undertake assessment activities, or the kinds of assessment we should undertake: we acknowledge that the organizations, institutions, and the wider educational, social, political, and cultural landscapes in which we operate are complex. Assessment in higher education is motivated by varied purposes, stakeholders, and approaches, many of which may be outside a library's power to influence. Our goal instead is to pose questions that we have been using to reflect more critically on our work. We are not calling for the Library Assessment Conference to be reframed in terms of impractical and unsustainable assessment: the opposite of practical is not an impractical assessment. Rather, our paper focuses on how we have been making efforts to engage in a more reflective practice, specifically in order to think about the ways in which assessment may or may not be aligned with social justice goals and how we might better connect our work with values of equity and inclusion.

To this end, we will begin by sharing some of the tensions we have come to feel in our work. We will highlight some of the motivating factors that brought us to our current state of questioning, including wider conversations about library assessment in the library and information science field. We will draw on Lise Doucette's qualitative analysis of Library Assessment Conference proceedings from 2006-2014 and, specifically, her discussion of motivations for assessment projects. We will then turn to a discussion of what David James Hudson calls the "practicality imperative" in librarianship and how critically exploring this imperative can open up productive approaches to our assessment work. We will close with some examples of the kinds of questions we have been asking ourselves, which are drawn from a variety of fields and perspectives, including recent work on assessment and social justice in the fields of institutional research and student affairs assessment.

\section{Sites of tension}

In our assessment work, we employ approaches which emphasize partnership and co-creation with users. While these methods lend themselves to a model of power-sharing with participants, we found it all too easy to bind the limits of the project to our own understanding of what is useful to the library. Our desire to do useful, actionable assessment work compels us to focus on questions with clearly articulated answers, on activities by which we can easily measure "use" or "impact." While we know many of us consider matters of equity and inclusion in our work, the three of us have-through challenging discussion and generous discomfort-come to realize that the extent to which a critical ethos permeates assessment work is limited, and we hope that by asking questions and exposing some of our own tensions and struggles around critical assessment work, we can challenge this status quo in meaningful and authentic ways.

We hope to open up space to imagine ways of embedding a critical perspective in all aspects of the assessment cycle: from deciding which projects to undertake, formulating questions and selecting participants, to how we analyze and communicate data. This is not easy or comfortable work, and in doing it, we must surface our assumptions and question precisely how we arrived at them. 
When we recruit participants, for example, we must ask ourselves what assumptions we enact when we seek to replicate professional norms. Who is excluded from a deceptively neutral representative sample? How does bias influence who we select-or who is available-to participate in studies? ${ }^{1} \mathrm{~A}$ critical or inclusive approach to recruitment asks us to recognize that our assessments live within systems and environments in which white cultural norms and values dominate. ${ }^{2}$ In a recent space assessment survey the authors conducted, responses were limited to those who already occupied the space of the library in order to describe current space use. This kind of assessment has value to our institution and to our stakeholders; however, if our recruitment is always limited to those who are already connected to the library, our sample populations will fail to incorporate those whose identities, experiences, or ways of knowing are already alienated by or excluded from the spaces (physical and otherwise) of the library.

But we also want to caution against turning an assessment lens exclusively toward members of marginalized communities without interrogating, first, how we frame the data that are collected and subsequently acting upon said data in ways that respond to or reduce found disparities. A critical perspective on data collection and analysis would rely on a perception of data not as objective truth but as subjective, situated, constructed, partial, and political. Acknowledging that data are not immune to the influence of systemic inequity and the ways in which our data collection and analysis practices reinscribe a hegemony of white normativity opens up space for us to re-examine outliers, reinterpret trends and redefine what we consider "evidence" or "research." ${ }^{3}$ We find ourselves and our colleagues wanting to advocate for change and propose projects that aim to better understand non-users or particular user groups. However, as a researcher in higher education assessment notes, "[I]t is not enough to demonstrate differences and inequality-we have plenty of studies that show disparities...but many of these studies fail to engender changes in society or higher education." ${ }^{4}$

\section{Critical librarianship and assessment}

As we have been considering assumptions inherent in our daily work, we have also been exploring how assessment is discussed and framed in professional conversations. In recent years, there has been a growing interest in taking critical and theoretical perspectives on all aspects of library work. Critical librarianship seeks to place library work "within a critical theorist framework that is epistemological, self-reflective, and activist in nature... [L]ibrarians that practice critical librarianship strive to communicate the ways in which libraries and librarians consciously and unconsciously support systems of oppression. Critical librarianship seeks to be transformative, empowering, and a direct challenge to power and privilege." ${ }^{5}$ Critiques of assessment from this perspective often focus on the alignment of library assessment with a culture of compliance, efficiency, and consumerism and an over-reliance on quantitative measures. ${ }^{6}$ While we are not going to spend time unpacking these critiques in detail here, and we do not have space to do full justice to them, we admit to finding some aspects of this work challenging. While one does not have to be a regular attendee at the Library Assessment Conference, Canadian Library Assessment Workshop, or LibPMC (International Conference on Performance Measurement in Libraries) in order to ask meaningful and important questions about assessment, we feel that the ways in which we as assessment practitioners are wrestling with the nuances and complexity of our work are not fully reflected in these arguments.

At the same time, we also wonder why assessment-focused conference papers and publications, often written by and for those whose primary professional role involves assessment, do not seem to engage in the same way with the valuable critical and theoretical perspectives that are being embraced by any number of sub-fields of LIS: from archival studies; ${ }^{7}$ cataloguing and classification ${ }^{8}$ spaces; ${ }^{9}$ and reference and instruction, including instructional assessment. ${ }^{10}$ So prominent has this strand of work become in the area of information literacy instruction and assessment that, in 2015, an entire article could be devoted to a review of a decade of literature about critical information literacy. ${ }^{11}$ In addition to specific areas of our work viewed through this critical lens, there is also a significant body of literature exploring issues of social justice, whiteness, inclusion, and equity in relation to library services, spaces, and resources. ${ }^{12}$

With the exception of critical instruction assessment, a great deal of assessment-focused literature continues to concentrate primarily on practical aspects of assessment, such as discussions of specific methods, techniques, or studies. Lise Doucette's bibliometric analysis of Library Assessment Conference (LAC) 
proceedings from 2006 to 2014 highlights the focus of the majority of papers on particular methods, competencies, and topics such as assessment of collections, spaces, and teaching and learning. ${ }^{13}$ She notes that the dominant purposes for assessment work articulated in the proceedings fell into two categories: improving the library and/or proving something about the library. ${ }^{14}$ In our own brief search of the 2016 LAC proceedings, the word "critical" comes up over 100 times, primarily in the context of critical thinking for students, what is critical for users in a space, and what is critical to demonstrate to our stakeholders, rather than in relation to reflective approaches to our own practices. We draw attention to this not with negative intention, but rather to highlight the opportunity before us to be more reflective of our practice as assessment librarians.

The practical is a necessary and important aspect of our work: we have given papers on specific case studies that aimed to provide conference attendees with practical takeaways and we have learned much from the community that we have taken back to our own institutions to help serve our faculty and students. However, we also feel the need to ask more questions about the ways in which systems of power and privilege might shape assessment and what that means for us, the profession, and our user communities. ${ }^{15} \mathrm{We}$ ask ourselves, "How do we create space for the critical and reflective, in addition to the practical, and what sort of questions might we pose to get there?" In David James Hudson's work on practicality, we find one frame by which to challenge our assumption of, and adherence to, the power of the practical.

\section{Reflecting on the "practicality imperative" (or, Practice makes perfect)}

In "The Whiteness of Practicality," Hudson makes clear, he does not question "our commitment to prioritizing user needs"; rather he interrogates how, in librarianship, practicality operates as a dominant value and a prescription that exerts influence, often unexamined, on our work. ${ }^{16}$ In the same way that whiteness "resides, in crucial part, in its occupation of a space of unmarked normativity" against which all "other" is measured and held relationally, practicality exists as a commonsensical foundation on which we produce and reproduce work and product in librarianship. ${ }^{17}$ Practicality is positioned as uncomplicated reality-the takeaways, toolkits, and "practical implications" on which we rely-while the nature of its manufacturing within an "environment...governed by expectations of efficiency, directness, brevity, speed" exists largely under the surface of its frequent deployment. ${ }^{18}$ Echoing Doucette's findings, Hudson lists the various outputs of our field: 'case studies, standards, best practices, how-to guides and 'cookbooks,' and the like-work, in other words, that might be described as drawing on the tangible, on-the-ground realities as subject matter and moving beyond questions to providing tangible, actionable answers." ${ }^{19}$

With his examination of the language of practicality that dominates the submission guidelines for LIS publications and conferences, Hudson establishes that the practical is privileged to occupy the space of reality in our field, while "the theoretical is definitionally disconnected from [it]." ${ }^{20}$ The dualism that he surfaces positions "practice [as] action, solutions, efficiency, the everyday, concreteness, reality; and theory [as] thinking, reflection, abstraction, problems, inapplicability, inefficiency." ${ }^{21}$ Yet for Hudson, theory is in fact a type of action that opens up the possibility of questioning the hegemony of the practical that provides us an entry point for challenging our devotion to a particular way of knowing and working that has long lived unchallenged.

We do not set out here to suggest there is no value in the practical; but rather, the practical's erasure of value in foundational critiques is problematic to assessment work that we do in service of our constituents. Our affinity for practicality is easily understood; we work in service of our communities and for said communities to see the benefits-"the results"-of our work, we must "take action." Libraries provide access; they afford convenience for the people who visit them and make use of their services. It is no wonder, then, that we would cleave to those same imperatives when discussing the basis of motivations for our work. Access is practical; the elimination of barriers is practical. However, "from another angle, the mobilization of shared conceptual frameworks that underpins our professional imperative to practicality can be read as a foundational reliance on existing ways of knowing, on received languages..." ${ }^{22}$ It is precisely through stepping back and questioning the way we have always done things that we begin to consider the ways in 
which our work has the potential to uphold inequities-in the questions we ask, the populations we survey, and the analyses we conduct.

To Hudson, as a profession, we are often engaged in "research without friction," research that will produce easily digestible answers or "lead to improved productivity and measurable successes." ${ }^{23}$ Our work at once facilitates and is motivated by the practicality imperative; and yet, as Doucette points out, "there is a lack of critical reflection and research about motivations for undertaking assessment work." ${ }^{24}$ She highlights the fact that in the LAC proceedings, motivations are vaguely articulated, if at all. Without a clear understanding of our own motivations, we cannot begin to critically interrogate the power structures and inequities that may underlie our assessment practices.

In Doucette and Hudson, we find a somewhat unlikely pair: one taking a systematic and practical approach to analysing the tangible outputs of the Library Assessment Conference, and the other centering the whiteness and domination of practicality as a hegemonic force in the work of librarianship. But in their work, we identify that which drives our current state of questioning-from Doucette, making more explicit the motivations of our work and the demands under which they are informed, and from Hudson, interrogating the position (accepted as normative and neutral) that practicality equals reality equals value.

Taking a more critical lens to our work, as Hudson and Doucette suggest, can open up important questions about why we are doing our work, how our own positions of power (institutional and personal) shape what we see as fitting topics for assessment, whose interests are being served, whether our work is excluding or further marginalizing already marginalized user groups, and the potential for doing our work meaningfully with users, not just about them.

\section{Critical questions for assessment practitioners}

In this spirit, we want to provide some semblance of a "takeaway"-a series of questions about how we do our work and what is at stake in our decisions. These questions were drawn from work on assessment and social justice in the fields of institutional research, student affairs assessment, and critical data studies. In our own work, we found it comforting to realize library assessment is not unique in grappling with these issues and complexities, and found these questions generative in beginning to move us forward. ${ }^{25}$

- How do our own identities, institutional positions, and perspectives shape our work?

- What is the purpose of the assessment, who decides what to assess, and who benefits from the work?

- Are we doing our work in ways that enable power sharing and engagement with user communities at all stages of the assessment cycle?

- What is considered "evidence" and who decides?

- What are the histories and contexts of the methods we choose, and how do these shape our work? Do these methods risk alienating or silencing voices?

- Whose voices are privileged in our recruitment practices? How do we avoiding "essentializing" communities at the margins?

- Are we engaging in data analysis and interpretation as a collaborative and social practice?

- How are the most vulnerable on our campuses being served by our assessment practice?

We are trying to create (or at least bring light to) a reality in which we hold awareness of the structures of power informing and motivating our work alongside our decisions about assessment activities, participant recruitment, or data analysis; and we acknowledge the difficulty (perhaps, impossibility) in achieving a balance in every project we undertake. It may, in fact, be impractical; but, for us, the value in asking difficult questions and challenging our assumptions is the hope that we move toward a more mindful and inclusive assessment practice.

-Copyright 2019 Ebony Magnus, Maggie Faber, and Jackie Belanger 


\section{Endnotes}

1. Karine Larose and Simon Barron, "How white is your UX practice?: inclusion and diversity in critical UX research," User Experience in Libraries: Yearbook 2017 (2017).

2. Brook, Ellenwood, and Lazzaro, "In pursuit of antiracist social justice."

3. Berg, "Quantitative Researchers"; Fernández, "Critical assessment,"

4. Hurtado, "The transformative paradigm," 290.

5. Garcia, "Keeping up with."

6. Lilburn, "Ideology and audit culture"; Nicholson, "The McDonaldization of academic libraries"; Quinn, "The McDonaldization of academic libraries?"

7. Cifor and Lee, "Towards an Archival Critique"; Cifor and Wood, "Critical Feminism in the Archives."

8. Drabinski, "Queering the catalog"; Roberto, Radical cataloging.

9. Drabinski, "Queering library space"; Elmborg, "Libraries as the spaces between us."

10. Accardi, "The feminist reference desk"; Maria Accardi, "Feminist Pedagogy for Library Instruction"; Accardi, Drabinski, and Kumbier, Critical library instruction; Pagowsky and McElroy, Critical library pedagogy handbook.

11. Tewell, "A Decade of Critical Information Literacy."

12. Brook, Ellenwood, and Lazzaro, "In pursuit of antiracist social justice"; Morales, Knowles, and Bourg, "Diversity, social justice, and the future of libraries"; Mathuews, "Moving beyond diversity to social justice."

13. Mohanty, Sahoo, and Dash, "Evolution of Library Assessment Literature."

14. Doucette, "Acknowledging the Political," 291.

15. Nicholson, "The "Value Agenda."

16. Hudson, "The whiteness of practicality," 205.

17. Hudson, "The whiteness of practicality," 213.

18. Hudson, "The whiteness of practicality," 212.

19. Hudson, "The whiteness of practicality," 207.

20. Hudson, "The whiteness of practicality," 210.

21. Hudson, "The whiteness of practicality," 210.

22. Hudson, "The whiteness of practicality," 212.

23. Hudson, "The whiteness of practicality," 212.

24. Doucette, "Acknowledging the Political," 288.

25. Magnus, Faber, and Belanger, "Towards a critical assessment practice."

Bibliography

Accardi, Maria T. The feminist reference desk: Concepts, critiques, and conversations. Sacramento, CA: Library Juice Press, 2017.

Accardi, Maria T. Feminist Pedagogy for Library Instruction. Sacramento, CA: Library Juice Press, 2013.

Accardi, Maria, Emily Drabinski,and Alana Kumbier, eds. Critical library instruction: Theories and methods. Duluth, MN: Library Juice Press, 2010.

Berg, Selinda Adelle. "Quantitative Researchers, Critical Librarians: Potential Allies in Pursuit of a Socially Just Praxis." In The Politics of theory and the practice of critical librarianship, edited by Karen P. Nicholson and Maura Seale, 225-35. Sacramento, CA: Library Juice Press. https://scholar.uwindsor.ca/leddylibrarypub/52.

Brook, Freeda, Dave Ellenwood, and Althea Eannace Lazzaro. "In Pursuit of Antiracist Social Justice: Denaturalizing Whiteness in the Academic Library.” Library Trends, 64, no. 2 (2015), 246284. https://doi.org/10.1353/lib.2015.0048. 
Cifor, Marika and Jamie A. Lee. "Towards an Archival Critique: Opening Possibilities for Addressing Neoliberalism in the Archival Field." Journal of Critical Library and Information Studies, 1, no. 1 (2017), 1-22. https://doi.org/10.24242/jclis.vli1.10.

Cifor, Marika and Stacy Wood. "Critical Feminism in the Archives." In Critical Archival Studies, Edited by Michelle Caswell, Ricardo Punzalan, and T Kay Sangwand. 1, no. 2

(2017). https://doi.org/10.24242/jclis.vli2.27.

DeLuca Fernández, Sonia. Critical Assessment. Webinar delivered for Student Affairs Assessment Leaders (SAAL) Structured Conversations series. December 9,

2015. http://studentaffairsassessment.org/files/documents/SAAL-SC-Critical-Assessment-sdf-9-dec2015-FINAL.pdf.

Drabinski, Emily "Queering the catalog: Queer theory and the politics of correction." The Library Quarterly, 83, no. 2 (2013) 94-111.

Drabinski, Emily. "Queering library space: Notes toward a new geography of the library.” Presented at the Thinking Critically: Alternative Perspectives and Methods in Information Studies, University of Wisconsin-Milwaukee, May 2008, 30-37. http://www.emilydrabinski.com/wpcontent/uploads/2012/06/EmilysThinkingCriticallypaper.pdf.

Doucette, Lise. "Acknowledging the Political, Economic, and Values-Based Motivators of Assessment Work: An Analysis of Publications on Academic Library Assessment." In Proceedings of the 2016 Library Assessment Conference: Building Effective, Sustainable, Practical Assessment, October 31-November 2, Arlington, Virginia. Edited by Sue Baughman, Steve Hiller, Katie Monroe, and Angela Pappalardo. Washington, D.C.: Association of Research Libraries, 2017. http://old.libraryassessment.org/bm doc/proceedings-2016.pdf.

Elmborg, James K. "Libraries as the spaces between us: Recognizing and valuing the third space." Reference \& User Services Quarterly. 50, no. 4 (2011): 338-350. http://dx.doi.org/10.5860/rusq.50n4.338.

Garcia, Kenny. "Keeping up with... Critical librarianship.” Association of College \& Research Libraries. http://www.ala.org/acrl/publications/keeping_up_with/critlib.

Hudson, David James. “The whiteness of practicality [postprint].” In Topographies of Whiteness: Mapping Whiteness in Library and Information Science. Edited by Gina Schlesselman-Tarango, 203-234. Sacramento: Library Juice Press, 2017. https://atrium2.lib.uoguelph.ca/xmlui/bitstream/handle/10214/11619/Hudson_Whiteness_Of_Pra cticality_IR_rl.pdf?sequence=6\&isAllowed $=y$.

Hurtado, S. "The transformative paradigm: principles and challenges.” In Critical approaches to the study of higher education: A practical introduction. Edited by Martínez-Alemán, A., Pusser, B, \& Bensimon, E.M. Baltimore, MD: Johns Hopkins University Press, 285-307.

Larose, Karine and Simon Barron. "How white is your UX practice?: inclusion and diversity in critical UX research." User Experience in Libraries: Yearbook 2017. CreateSpace Independent Publishing Platform, 23-33.

Lilburn, Jeff. "Ideology and audit culture: standardized service quality surveys in the academic library." Portal: Libraries and the Academy 17, no. 1 (2017): 91-110.

Mathuews, Katy. "Moving beyond diversity to social justice." Progressive Librarian no. 44. http://www.progressivelibrariansguild.org/PL/PL44/006.pdf. 
Magnus, Ebony, Maggie Faber, and Jackie Belanger. “Towards a critical assessment practice.” In the Library with the Lead Pipe. http://www.inthelibrarywiththeleadpipe.org/2018/towards-critical-assessmentpractice/.

Mohanty, Basudev, Jyotshna Sahoo, and Nrushingh Kumar Dash. "Evolution of Library Assessment Literature-A Bibliometric Analysis of LAC Proceedings.” In Proceedings of the 10th International CALIBER conference, Shimla, Himachal Pradesh, India, March 12-14,

2015. http://ir.inflibnet.ac.in/bitstream/1944/1848/1/9.pdf.

Morales, Myrna, Em Claire Knowles, and Chris Bourg. "Diversity, social justice, and the future of libraries." portal: Libraries and the Academy 14, no. 3 (2014): 439-451.

Nicholson, Karen P. "The 'Value Agenda': Negotiating a path between compliance and critical practice [keynote address].” Canadian Libraries Assessment Workshop (CLAW). University of Victoria, October 26, 2017.

Nicholson, Karen P. "The McDonaldization of academic libraries and the values of transformational change." College \& Research Libraries ACRL 76, no. 3 (2015): 328-338.

Pagowsky, Nicole, and Kelly McElroy, eds. Critical library pedagogy handbook. Volumes 1 \& 2. Chicago, IL: Association of College and Research Libraries.

Quinn, Brian. “The McDonaldization of academic libraries?" College \& Research Libraries 61, no. 3 (2000): 248-261. https://doi.org/10.5860/crl.61.3.248.

Roberto, K. R., ed. Radical cataloging: Essays at the front. Jefferson, NC: McFarland \& Company, Inc., 2008.

Tewell, Eamon. "A Decade of Critical Information Literacy: A Review of the Literature." Communications in Information Literacy 9, no. 1 (2015): 24-43. https://doi.org/10.15760/comminfolit.2015.9.1.174. 